\title{
PILAR MUNÁRRIZ SÁNCHEZ Y LUIS LEAL CRESPO, DOS PROFESORES AL EXILIO. DESDE GIRONA A CARACAS
}

\author{
Pilar Munárriz Sánchez \& Luis Leal Crespo, \\ two Teachers in Exile from Girona to Caracas
}

\section{Salomó Marquès Sureda ${ }^{\&}$}

Fecha de recepción: 17/10/2018 • Fecha de aceptación: 25/10/2018

Resumen. El documento ofrece parte de las memorias inéditas escritas en Caracas por la maestra e Inspectora de primera enseñanza Pilar Munárriz. Ejerció de inspectora en las provincias de Girona y Álava. Las memorias las escribió el año de la muerte de su marido Luis Leal Crespo, profesor en la escuela Normal de La Laguna, Oviedo y Girona. Cuando Cataluña fue ocupada por las tropas rebeldes el matrimonio se exilió a Francia. Posteriormente marcharon a la República Dominicana donde Leal continuó trabajando en el campo de la enseñanza. De la dictadura de Trujillo tuvieron que marchar por presiones políticas estableciéndose en Caracas. En la capital venezolana Leal ejerció en diferentes colegios dirigidos por colegas y amigos republicanos exiliados. Finalmente creó su propia obra: el Colegio Leal. Las memorias de Munárriz permiten conocer la vida familiar de un matrimonio de maestros en el exilio, su labor profesional y los avatares políticos que marcaron su vida, tanto en Santo Domingo como en Venezuela.

Palabras clave: Exilio maestros republicanos; Pilar Munárriz; Luis Leal Crespo; Colegio Leal; Educación en República Dominicana: Educación en Venezuela

Abstract. This article offers part of the unknown memoirs written in Caracas by the teacher and inspector of primary education Pilar Munárriz, who had worked as inspector in the Spanish regions of Girona and Álaba. These memoirs were written the year her husband, Luis Leal Crespo, died. He worked as a teacher at the Teacher Education Schools of La Laguna, Oviedo and Girona. Afterwards, the couple left for the Dominican Re-

\footnotetext{
\& Universitat de Girona. Departament de Pedagogia. Plaça Sant Domènec 9, 17071 Girona. salomo. marques@udg.edu
}

Cómo citar este artículo: Marquès Sureda, Salomó. «Pilar Munárriz Sánchez y Luis Leal Crespo, dos profesores al exilio. Desde Girona a Caracas». Historia y Memoria de la Educación 9 (2019): 781-814. 
public where Leal continued to work in the field of Education. With the arrival of Trujillo's dictatorship, they had to leave the country due to political pressures, and they finally settled in Caracas. In the Venezuelan capital Leal worked in different schools managed by his Republican colleagues and friends in exile. Finally, he created his own: the Leal School. These memoirs contribute to our knowledge of how family life was for a married couple of teachers in exile and it looks at the professional and political epiphanies that marked their lives, both in Santo Domingo and in Venezuela.

Keywords: Republican teachers in exile, Pilar Munárriz, Luis Leal Crespo, Colegio Leal, Education in the Dominican Republic, Education in Venezuela.

\section{INTRODUCCIÓN}

El año 2002 la Universidad Central de Venezuela publicaba La labor educativa de los exiliados españoles en Venezuela ${ }^{1}$ obra del arquitecto Juan José Martín Frechilla y del que escribe estas páginas. En el capítulo sobre los maestros hablábamos del Colegio Leal fundado por el profesor Luis Leal Crespo que había ejercido durante la monarquía alfonsina y la República en varias Escuelas Normales (La Laguna, Oviedo, Girona). Por lo que se refiere al profesorado del centro, hacíamos mención de «su esposa Pilar Munárriz, inspectora de primera enseñanza de Álava». ${ }^{2}$

En el momento de publicar el libro poca cosa sabíamos del matrimonio Leal-Munárriz. Posteriores investigaciones nos han permitido conocer la interesante personalidad pedagógica de Luis Leal que fue profesor y director de la Escuela Normal de Girona durante la guerra y, también de su esposa, inspectora en la provincia gerundense durante algunos años de la República en paz y, posteriormente, en los años de guerra. Desde Girona, territorio de frontera, marcharon al exilio por La Jonquera. Primero a Francia, después a bordo del Cuba a la República Dominicana y, finalmente, a Venezuela donde se instalaron de manera definitiva y continuaron trabajando en el campo de la educación.

\footnotetext{
${ }^{1}$ Salomó Marquès Sureda-Juan José Martín Frechilla, La labor educativa de los exiliados españoles en Venezuela (Caracas: Fondo Editorial de Humanidades y Educación, Universidad Central de Venezuela, 2002).

${ }^{2}$ Marqués Sureda-Martín Frechilla, La labor educativa, 83.
} 
El año 2016, Nere Leal Munárriz, una de las hijas del matrimonio, residente en Estados Unidos, conectó conmigo y me regaló las memorias que su madre había escrito el 1976 en Caracas. Las titulaba: Memorias anecdóticas de una exiliada "por la gracia de Franco» ${ }^{3}$ con la siguiente nota aclaratoria en la primera página: «Todo lo narrado es verídico. No tengo capacidad para novelar». Se trata de un texto mecanografiado de 101 páginas ${ }^{4}$ escritas el año que murió su esposo.

En el texto que sigue presento una selección de estas memorias. He incorporado en nota a pie de página algunas observaciones para una mejor comprensión de la situación de los maestros exiliados. Por otra parte, la hija ha incorporado entre paréntesis algunas observaciones que aclaran palabras del vocabulario caraqueño. También están entre paréntesis los números indicativos de las páginas del texto original.

Las memorias de Pilar Munárriz constan de dos partes bien definidas. En una primera narra recuerdos de infancia, de vida familiar, de años de estudios y, finalmente, de su trabajo primero como maestra y posteriormente, durante la República en paz y en guerra, como inspectora. La segunda parte tiene dos protagonistas, Pilar y Luis Leal, su no-

\footnotetext{
${ }^{3}$ El texto íntegro puede consultarse: https://dugifonsespecials.udg.edu/handle/10256.2/14408?show=full. Se ha conservado el original con algunas notas incorporadas por su hija para una mejor comprensión del texto.

${ }^{4}$ El índice del manuscrito es el siguiente:

-Donde la peregrina hace un resumen de su historia para que el lector, una vez leído, siga o no adelante (p. 2).

- Capítulo que amplía datos sobre mi infancia, juventud estudiantil y estado adulto hasta el momento que «él» entró en mi vida (p. 8).

-Donde se narran las secuencias por las cuales lo que prometía ser una vida gris cambia de color radicalmente (p. 19).

- Continua el capítulo anterior que se corta al terminar mi experiencia como maestra rural y subo de categoría (p. 27).

- ¡Guerra Civil! (p. 33).

-Donde se transcriben párrafos de una carta de Alejandro Casona a Luis (inédita). Testimonio histórico irrefutable y continua mi vida afortunadamente escrita en lo sucesivo en plural (p. 42).

- Breve interludio de felicidad hasta el regreso a la vorágine de la guerra (p. 46).

— «iberté, Egalité, Fraternité» (p. 51).

—Siguiendo la ruta de Cristóbal Colon llegamos a la «Hispaniola» (p. 60).

- iVenezuela! (p.68).

-Colegio Leal (p. 76).

-El 23 de enero. Seguimos informando (p. 84).

-El terremoto 1967 (p. 90).

-Y aquí doy fin a mis memorias con la muerte de mi otro «yo» (p. 92).

-Colofón (p. 101).
} 
vio y más tarde esposo, profesor en diferentes Escuelas Normales de la geografía española. En esta segunda parte, la que nos interesa, narra todo el itinerario de exilio: la salida a Francia por La Jonquera, la estancia en el país vecino, la salida hacia la República Dominicana, las tensiones políticas en dicho país, la marcha y el definitivo establecimiento en Venezuela. Explica el trabajo de Luis como profesor en diferentes colegios compartiendo enseñanza con otros colegas republicanos exiliados, hasta culminar con la creación de su propio centro, el Colegio Leal. En los capítulos dedicados a Venezuela también narra los avatares políticos y las consiguientes repercusiones en el colegio Leal.

\section{BREVE RESEÑA DE LOS DOS PROTAGONISTAS DEL EXILIO}

Luis Leal Crespo (Madrid, 1903-Caracas, 1976). Estudió en la Escuela Normal de Madrid. Finalizados los estudios ingresó en la Escuela Superior de Magisterio (1921-1925). Becado por la Junta para la Ampliación de Estudios visitará colegios de Francia, Bélgica y Suiza. El 1930 es nombrado profesor en la Escuela Normal de Oviedo, después de ejercer en la Escuela Normal de la Laguna, en Canarias. Ya durante la república en guerra, el febrero de 1937, es nombrado maestro de clases de español en Beziers (Francia) y, en octubre del mismo año, profesor numerario de Cuestiones Económicas y Sociales en la Escuela Normal de Girona, donde posteriormente también enseñará Metodología de la Historia. En enero de 1938 es nombrado director del centro. ${ }^{5}$ De profundas convicciones republicanas no se le conoce militancia en partido político. Pasó la frontera camino del exilio por La Jonquera acompañando una colonia escolar. Un hermano de Luis, Fernando, inspector de primera enseñanza en Mallorca fue asesinado por los rebeldes durante los primeros días de la sublevación militar. Su esposa - Nita- y sus hijos recibieron ayuda del matrimonio Leal-Munárriz.

Desde Francia salió con su esposa con destino a la República Dominicana. ¡Para evitar caer en manos de la dictadura franquista y de los alemanes que habían ocupado Francia, caerán en manos de Trujillo! Durante la estancia en la República Dominicana ejercerá el magisterio. De todas maneras, tendrá que marchar del país por razones políticas.

\footnotetext{
5 Joan Puigbert, La Normal de Girona i el magisteri públic (1914-1936) (Girona: Universitat de Girona, 1994), 117 y ss.
} 
La familia salió hacia Venezuela donde se afincó definitivamente. Allí trabajó de profesor en diferentes escuelas dirigidas por maestros republicanos exiliados. Finalmente creará su propio centro, el Colegio Leal, en el que prácticamente trabajó hasta su fallecimiento.

Pilar Munárriz (San Sebastián, 1906-Caracas, 1992), era la pequeña de cinco hermanos: Maria, Enrique, Carmen, Santiago y Pilar, del matrimonio Eufrasio Munárriz y Quiteria Sánchez. La primera etapa de los estudios obligatorios los realizó en Vera de Bidasoa y Madrid, interna en dos colegios de monjas. Expulsada del colegio madrileño, finalizará los estudios obligatorios en una escuela pública. En San Sebastián estudiará el bachillerato y, posteriormente obtendrá el título de maestra. El 1928 ingresará en la Escuela Superior del Magisterio formando parte de la primera promoción de la República.

La primera población donde ejercerá de maestra será Aceituna, en la provincia de Cáceres. El noviembre de 1932 será nombrada inspectora en la provincia de Girona donde permanecerá hasta febrero de 1934 cuando, por concurso de traslado, marchará a Alaba. En la revista El Magisterio gerundense se despide de los maestros con estas palabras:

A los maestros de la $4 .{ }^{a}$ Zona. Con motivo de haber sido trasladada a Vitoria y en la imposibilidad de despedirme de todos personalmente lo hago por medio del «Magisteri Gironí». Siento haber abandonado la provincia de Gerona donde fui acogida tan favorablemente y de la que tengo un grato recuerdo. En ella encontré buenos compañeros, maestros laboriosos y amistades sinceras, pero he tenido que dejarla para cumplir mejor mi deber profesional. El no saber el idioma catalán me impedía el diálogo con los alumnos del que surge la idea de los conocimientos que el niño posee y se pueden aclarar sus dudas y titubeos. Faltando esa base de comprensión es inútil intentar una labor eficaz. Desde estas columnas me despido de todos en general, pero particularmente de los maestros de ambos sexos de mi zona, así como de los simpáticos alumnos. Tanto a unos como otros agradezco la simpatía, deferencias y delicadezas que en mis visitas han tenido conmigo. Abril $1934 .^{6}$

\footnotetext{
${ }^{6}$ Miquel Juhera i Cals, La Inspecció d'Ensenyament des dels seus origens a la Segona República. Edición privada ciclostilada, 168-169.
} 
Se casará, durante la guerra, con Luis Leal en el consulado de Beziers (Francia) donde trabajaba su esposo. Volverá a Girona el 1937. En el mes de febrero de 1939 desde la capital gerundense marchará a Francia con su esposo. De Francia a la República Dominicana y, finalmente, a Venezuela donde residirán de manera definitiva. En el exilio caraqueño en algunas ocasiones (no muchas) ayudó a su marido en la escuela.

El matrimonio Leal-Munárriz tuvo tres hijos, todos nacidos en América: Nere, Luís Enrique y Marisa.

A la muerte de su esposo escribió unas memorias de las que ofrezco los fragmentos relacionados más directamente con el exilio y la enseñanza.

\section{Memorias anecdóticas de una exiliada «por la gracia de Franco»} (fragmentos)

El año 1937 Pilar Munárriz y Luis Leal se han casado en el consulado español de Beziers donde él trabajaba. Han viajado a París.

\section{CAMINO DEL EXILIO Y PASO DE FRONTERA}

[...] (p. 47) Regresamos a Beziers donde también el calor es abrumador así que vimos con alegría el momento en que nos llamaron a España con destino a Gerona, él de profesor de la Escuela Normal y yo de Inspectora. Volver a vivir en Gerona me agradó por su buen clima, pero sufrí una desilusión al ver destruidas las iglesias artísticas si bien la excusa había sido que las quemaron por culpa de franco-tiradores, apostados en ellas el principio de la contienda.

Mientras estuvimos en Gerona íbamos a una fondita modesta a comer. Llegó un momento en que no había papas y las sustituían por nabos. A la quinta semana de nabos renunciamos a volver y nos inscribimos en un comedor popular del gobierno, donde todavía el abastecimiento era suficiente.

Allí nos juntábamos personas de todas las categorías sociales pues ya éstas no existían ante la necesidad perentoria de comer. En este co-

\footnotetext{
7 Entre paréntesis figura el número de página del texto original.
} 
medor nos sucedió un día un hecho conmovedor. Gracias a esta verborrea que tenemos los españoles de hablar a gritos oímos la historia de unos vecinos de mesa que contaron que venían del desastre del frente del Ebro. En la retirada y con el rebullicio que se armó al querer huir todos los civiles del infierno de los tiros y bombardeos la gente perdía sus familiares y luego se encontraban o no. Nuestros vecinos de mesa habían perdido una niña de unos ocho años y no habían sabido nada de ella a pesar de todas las gestiones hechas. Como en las mesas a medida que se comía (p. 48) el que terminaba se levantaba para ser sustituido por otros, nosotros nos tocó el turno con un aviador al cual relatamos lo que acabábamos de oír. ¿Y cual no sería nuestro asombro al ver al aviador levantarse, ir a la otra mesa, preguntar por el nombre de la niña y al saberlo decirles?: «Tranquilícense ustedes que su niña está muy bien atendida y mimada en nuestro cuartel en Barcelona. La encontramos sola y llorando en las afueras de Teruel y la tenemos de mascota. Pueden ir mañana mismo a recogerla». ¿Verdad que parece un cuento?... Pues como ese caso ¡cuantos habrá habidos afortunados o desgraciados!

Se acercaba la debacle hacia Cataluña. Yo supe, por medio de mi hermana María que me escribió desde Londres, de la afortunada muerte de mi papá en San Sebastián. Y digo afortunada, porqué fue de repente y sin darse cuenta y ello le evitó los sinsabores de sabernos en peligro ante la catástrofe final.

Cuando se preveía el desastre nos vino de Barcelona una Sra. joven con una niña de pocos años enviada por el esposo amigo de Luis para que le ayudáramos a pasar la frontera. Luis decidió que ya era el momento en que las mujeres estorbábamos más que otra cosa y consiguió un camarada con vehículo que nos pudiera acercar lo más posible a Francia. El tipo que nos llevó decía que había llegado el momento en que no había matrimonios y que cada uno se podía juntar con lo que encontrara o le apeteciera. Entre los dos yo me salvaba pues María (mi compañera) era francamente guapa. Nos «perdimos» de él y quedamos varadas en un pueblecito a bastantes kms. de la frontera. Apareció mi Luis buscándonos y consiguió meternos en un camión con cañón antiaéreo donde escondidas llegamos a la etapa final.

Ya los franquistas bombardeaban impunemente a la gente que huía, en toda clase de medios de locomoción, pero la frontera se abría (p. 49) 
y cerraba como si fuera una oficina y a las seis de la tarde ya no dejaban pasar a nadie. A todo esto, la niña tenía tosferina y no hacía más que toser y vomitar con gran desesperación de su madre que a fuerza de ruegos consiguió nos amontonaran en un coche para resguardarnos de la lluvia y frío de enero.

Otra vez aparece Luis providencialmente a tiempo para ver a un grupo de niños, con dos maestros, envueltos en mantas y dispuestos a dormir al aire libre por estar cerrada la frontera. Se acerca al Director y le dice: «Si yo consigo que les dejen pasar la frontera ¿aceptan a estas dos mujeres, que pertenecen a la enseñanza, el que pasen con Vds. como personal de su Colonia?» El Maestro acepta encantado y mi marido ni corto ni perezoso se acerca a aquellos soldados gigantescos más o menos moros que, al mando de un oficial, ponían cara feroche al enemigo, y en su buen francés expone la situación dramática de esos niños mojándose a la intemperie. Conmueve las fibras sensibles del capitán y nos dejan pasar. Cuando el teniente vio que Luis me despedía abrazándome y se volvía a España le dice asombrado: ¿ «Pero Vd. no se queda?». A lo cual le contestó Luis que había dado permiso para pasar a las mujeres y los niños pero que él pasaría cuando lo hicieran los hombres pues él estaba movilizado y debía cumplir con su deber hasta el último momento. El francés se quedó asombrado y le apretó la mano muy efusivamente. ${ }^{8}$

Bueno, ya en Francia me encuentro sola completamente pues María y los demás habían sido llevados en un autobús a un refugio escolar. Un policía francés de los de capita galantemente me ayuda y carga una maleta hasta donde me puede orientar sobre el pueblo más cercano. ${ }^{9}$ Como pude llegué y me encuentro con dos maestras que me conocían por haber visitado sus escuelas. Cuando me oyen (p. 50) «champurrear» el francés deciden acogerse bajo mis alas protectoras y me llevan para dormir en el suelo de una oficina gentilmente cedida por sus dueños para ese menester en la noche. Al día siguiente volví otra vez a la fron-

\footnotetext{
${ }^{8}$ Seguramente el paso de frontera fue por Le Perthus, a cuatro quilómetros de La Junquera. Es el paso fronterizo por el que marcharon millares de republicanos.

${ }^{9}$ Se trata de La Boulou, a pocos kilómetros de Perpignan. Desde Le Boulou la mayoría de republicanos fueron dirigidos al campo de concentración de Argelès. A pie y «acompañados» por fuerzas militares francesas.
} 
tera pues había visto a mi cuñada (Nita, viuda de Fernando Leal) ${ }^{10}$ y mis sobrinos que estaban pendientes para pasar. Tengo la suerte de encontrarles, pero viene acompañada de otra señora con varios hijos y de la cual no se quiere separar. Total que me veo aumentada la familia y la responsabilidad. Nita me da una sortija valiosa para que la empeñe pues necesita comprar ropa para sus hijos que están ateridos de frío. Ante la duda de que fuera robada me dieron 1.000 francos. Hay que tener en cuenta que el dinero republicano que llevábamos no lo aceptaba nadie. Me encuentro con Mme. Bouffard nombre que debo escribirlo con mayúscula por lo que voy a contar.

SRES. LEÓN Y ÁNGELES BOUFFARD. Matrimonio suizo entusiastas de España fundadores de un Comité de ayuda suiza a los niños republicanos. Los habíamos conocido en Gerona y habían nombrado a Luis (con quien se entendían en francés) su representante para las relaciones con el Ministerio de Educación en todo lo que se refiriera a las Colonias de niños que protegían con ropa, comida, libros, etc. Todavía hoy nos carteamos y todos los años pasan unos meses en Palma de Mallorca, donde a veces les visitan los antiguos colonos.

Como digo, antes me encuentro con esta señora y me cita en un café para que hablemos. Pero nuestra estancia en Francia merece capítulo aparte.

\section{LIBERTÉ, EGALITÉ, FRATERNITÉ}

Tres palabras que desde la Revolución francesa iluminaron el Mundo. Con respecto a los exiliados, podemos decir que la primera no existió para nosotros. La segunda sí, ya que todos nos igualamos en la desgracia, y de la tercera tengo que reconocer, salvo la excepción de lo que voy a contar ahora, que el pueblo francés la ejerció plenamente. Por lo menos por lo que respecta a nosotros hallamos siempre maravillosa acogida en todas partes.

LA EXCEPCIÓN. En el pueblo de la frontera cuyo nombre no me acuerdo (las personas y casos desagradables procuro siempre olvidar-

\footnotetext{
${ }^{10}$ Inspector en Mallorca, fusilado por un grupo de falangistas el 27 de agosto de 1936 cerca de Raixa. Durante la república había ordenado la clausura de escuelas de monjas.
} 
los, pues es la forma de acumular «reconcomios») fui al café donde me había citado Mme. Bouffard. Se me acercó un gigante mesonero para preguntarme qué quería tomar y yo le dije que en el momento nada ya que esperaba una Sra. Un rato después vino la dueña con malos modos y le repetí la explicación. Pero pasaba el tiempo y Ángeles no venia. Yo, tragándome las lágrimas de la humillación de no tener dinero para pagar ni un vaso de agua, seguí aguantando hasta que de malos modos me echaron del café. Horas más tarde encontré a Mme. Bouffard la cual me explicó le había sido imposible acudir a la cita. Le conté lo que me había sucedido, y ello fue suficiente para que indignada nos llevara a las once personas y con nuestros bártulos ocupáramos unas cuantas mesas haciendo una consumición mínima.

Si yo hubiera estado sola me hubiera quedado con ella como ayudante, pero en su coche no cabíamos tantas personas. Nos pagó taxis hasta Perpignan donde la «Casa de España» acogía a los refugiados. Y allá nos fuimos a compartir la paja del suelo en el salón de actos que nos cedieron para dormir. Y nos alimentaban modestamente, pero aquellas patatas que nos daban nos resucitaban (p. 51bis), así como el pan francés y otras exquisiteces que no conocíamos desde hace tiempo.

A la «Casa de España» venían familias simpatizantes de la causa española y se llevaban a sus casas a los que podían. Yo había visitado en el Hotel a mi primo Jesús Laizaola el cual me ofreció mandarnos a los 11 a un refugio vasco los cuales estaban muy bien organizados, pero mis acompañantes no aceptaron la oferta pues siempre estaban pendientes de alguien que les faltaba, como yo misma que no sabía que había sido de Luís.

Acepté la hospitalidad de un matrimonio a quienes les caí bien. El era jefe de los jardineros de la Villa y me cedieron la habitación de uno de los hijos estudiante. ¡Qué bondad de familia! Ella no me consentía ni lavarme un pañuelo y me daban unos bistefs de medio kg. "para engordarme». Me dijeron que con ellos me quedaría hasta que apareciera mi marido y luego los dos hasta nuestro viaje a América, con el cual todos soñábamos.

Para no serles gravosa seguía yendo a la «Casa de España» siempre con la esperanza de saber de mi Luis. Un día saliendo del comedor lo veo esperándome. Flaco, demacrado, pero vivo. 
Nos contó que en Figueras acabando de salir de una casa una bomba la destruyó. Que pasó la frontera a pie y se salvó de ir a un Campo de concentración (donde los hombres eran llevados). ${ }^{11}$ ("iOh Libertad, Libertad, cuantos crímenes se cometen en tu nombre”!) gracias a su francés y al documento de identidad que tenía de cuando vivía en Beziers.

Los Sres. Ferrand, como habían prometido, nos llevaron a su casa, pero Luis decidió nos trasladáramos a Beziers donde le quedaban amigos y podría trabajar en algo. Allí estuvimos con la familia Tejedor, un catalán casado con una francesa que tenía una imprenta y un niño, Gilbert, a quien yo entretenía bastante.

(p. 52) La FRATERNIDAD nos la demostraron los maestros franceses de Beziers los cuales se turnaban diariamente para invitarnos a almorzar. Nos daban verdaderos banquetes hasta que los convencimos que con ellos nos perjudicaban pues nuestros estómagos no estaban para esos trotes. Pero los domingos hacíamos una excepción, ya que la sobremesa se podía alargar. Con esa costumbre de los franceses del vermout, el vino blanco para el pescado, el rojo para la carne y los licores, a mí las mezclas se me subían a la cabeza y me soltaban la lengua, quitándome la timidez de hablar mi francés traducido de forma literal, con lo cual se morían de risa con lo que les contaba y las tragedias se convertían en comedias a través de mi narración.

Una anécdota que les encantaba oírnos es la de Luis cuando llegó a Barcelona después de su escapada de Oviedo. En esta capital se encontró con que los mandamás eran gente de Oviedo a quienes conocía y que lo recibieron con los brazos abiertos. Para hacer no sé qué gestión, uno de los jefazos puso a la disposición de Luis un coche conducido por un loco miliciano acompañado de otro bien armado, que lo llevaron por las calles de Barcelona a velocidades supersónicas, tocando el claxon como si la misión fuera de vida o muerte, sorteando las calles atestadas de gente y con peligro de matarse de un modo nada heroico. Todo para conseguir un pase para ir a Francia.

A su paso por la frontera se fijan en que lleva puesto un anillo de oro con un escudo grabado. Lo menos que se creyeron fue que era un mar-

\footnotetext{
${ }^{11}$ En la playa, además del campo de concentración de Argelès, se hallaban a pocos kilómetros el campo de Le Barcarès y el de Saint Cyprien. En Collioure se instaló un campo de castigo.
} 
qués y a fuerza de malas palabras, muy de moda entonces, y de llamadas telefónicas consiguió que no le quitaran el anillo, que lo había intercambiado yo por el suyo con una cabeza de Ramsés muy artística y que había sido de su padre. El mío también procedía de mi papá el cual con sus manías de hijodalgo había mandado grabar el escudo de los $\mathrm{Mu}$ nárriz, blasón que casi todos los vascos tenían.

Y después de este inciso sigo con nuestra estancia en Beziers. Pudimos cartearnos con los Sres. Bouffard y nos comunicaron que los niños de sus colonias (no todos) estaban en un refugio en Villefranche du Perigod. ${ }^{12}$ Que andaban realengos y que si estábamos dispuestos para ir a cuidarlos mientras se solucionaran sus problemas. Aceptamos y a Villefranche nos fuimos.

Situado en una región famosa por sus rutas prehistóricas y para los grandes "gourmets» por sus trufas en foie gras, el pueblo nos resultó acogedor y sus habitantes nos trataron bien al comprobar poco tiempo después que aquellos niños no eran unos salvajes como los juzgaron al principio. Tiempo después vino con nosotros Nita y los suyos.

Luis con su actividad y autoridad puso orden en el caos del principio y con la ayuda del Comité Suizo que proporcionaban raciones extras de alimentos, tal vez los niños refugiados mejor cuidados de Francia fueron los nuestros.

Un industrial que tenía fábrica de enlatados nos traía vainitas frescas para picarlas, sacarles los hilos y las puntas y dejarlas listas con lo cual el personal de la colonia ganaba unos francos extras nada despreciables.

Las tardes de buen tiempo salíamos al campo. Encontramos una acequia de riego con un remanso que nos permitía a todos bañarnos y tomar el sol. Los trajes de baño los hicimos aprovechando ropas de punto mandadas por los suizos. Los niños cuando llegamos tenían sarna, pero con aquellos baños y una pomada mandada por el boticario que Luis y yo restregábamos con nuestras manos a los sarnosos conseguimos en una semana erradicar ese baldón propio de la gente sucia. $[\ldots]$

\footnotetext{
12 Población de la comarca de la Dordogne que no llegaba a los mil habitantes.
} 
(p. 54) Hacíamos excursiones por los alrededores. Fuimos a visitar una granja de pollos y nos obsequiaron con varias docenas de huevos nada despreciables. Los campesinos cuando pasábamos cerca de sus campos nos daban permiso para atiborrarnos de cerezas o de la fruta del tiempo dándose cuenta de nuestras ávidas miradas y para evitar tentaciones.

Teníamos tres chicas jóvenes, nietas de la cocinera, refugiadas también que la ayudaban y hacían la limpieza. Pronto los mozos del lugar las cortejaron y tiempo después se casaron con ellas. También a una maestra, simplona pero bonita, la cual terminó casándose con un suizo, mandado por los Bouffard que quiso vernos aprovechando sus vacaciones. La historia de esos amores es digna de contarse, por haber sido yo la «culpable» de las relaciones. El muchacho ¡cómo no! era relojero. Nos acompañó en nuestros paseos y, en el prado donde hacíamos gimnasia con los niños antes del chapuzón, un día les enseñó una gimnasia de lo más divertida que no era la sueca más o menos monótona. La suya consistía en hacer movimientos imitando los oficios diversos, carpinteros, albañiles, leñadores, etc. lo cual encantó a nuestros muchachos.

Cuando se fue a su país comenzó a cartearse con la maestrita la cual todavía no sabía un «mot» de francés, así que era yo quien le hacía los borradores para sus contestaciones, aumentando los defectos de lenguaje, para despistar.

[...] Después muchos meses sin saber nada de los niños de sus padres, por medio de la Cruz Roja Internacional (en Suiza ¡como no!) fueron los niños sabiendo de ellos. Unos estaban en España y los reclamaban, otros en Francia en otros refugios y querían tenerlos consigo como es natural.

Tuvimos que relacionarnos con el Consulado español (ya de Franco) para repatriar a los niños que debíamos mandar a su Patria. Entre ellos teníamos a un chiquitín huérfano y no había más remedio que entregarlo. Este niño había sido atendido últimamente por dos hermanas solteronas las cuales le habían volcado todo su afecto. Su desesperación fue grande al pensar que sería internado en un asilo y todas las gestiones que se hicieron para que se quedara resultaron infructuosas. Con nuestra colaboración redactamos mensajes (p. 57) e incluyendo algún 
dinero se lo cosieron en su ropa rogando a las personas de la Institución española que lo recibiera ponerse en contacto con las personas que querían protegerlo. En efecto, al cabo de algún tiempo tuvieron noticias y tras muchos trámites y gastos consiguieron adoptarlo y llevarlo con ellas a Villefranche. Después he sabido que el niño, ya hombre, ha sido el doble cayado para su vejez. (Siempre he pensado que las buenas acciones pagan en esta vida sin tener que esperar a la otra, más o menos incierta).

Teníamos otro niño tan pequeño que casi no sabía hablar. Un día de invierno estaba sentado a sol y murmuraba solito como una oración. Curiosa le pregunté qué es lo que musitaba y a duras penas pude entenderle lo que no hacía más que repetir, su himno al Sol, fuente de nuestra vida. Decía así: «Sol, solito — caliéntame un poquito- para hoy, para mañana-para toda la semana...». Sin comentarios.

Esperanza se vino de París al acabársele los ahorros ya que entretanto hacía gestiones en el S.E.R.E. ${ }^{13}$ con el fin de que fuéramos incluidos en algún barco de los que salían para América. Por dos veces estuvimos en lista para ir a México, pero renunciamos por la responsabilidad moral que teníamos con los niños. Al fin cuando ya solo quedaban en el refugio las personas que no querían movilizarse, entre ellos $\mathrm{mi}$ cuñada Nita con sus hijos, para los cuales consiguió Luis cupo en la Escuela francesa y ambos hicieron sus estudios en los primeros puestos (me refiero a los dos varones), nos decidimos a trasladarnos a París. Mi cuñada no quiso gestionáramos viaje para ella y los suyos ante el temor de que el barco fuera hundido por los alemanes pues ya entonces había comenzado la llamada Segunda Guerra Mundial (p. 58) que ojalá sea la última.

La «Ville lumière! estaba en sombras. Triste, con sus luces apagadas u ocultas, sus monumentos tapados con sacos de arena y sus magníficos museos vacíos de sus obras maestras. Cuando hacíamos colas en los distintos Departamentos para gestionar los papeles que necesitábamos irrumpía la policía para solicitar nuestra documentación y nos entristecía ver a compatriotas cazados en esa trampa inhumana.

\footnotetext{
${ }^{13}$ Servicio de Evacuación de Refugiados Españoles o Servicio de Emigración de Refugiados Españoles creado el mes de febrero de 1939 en París por el presidente del gobierno Juan Negrín.
} 
Se nos había caducado el visado para ir a México y en aquellos momentos no teníamos más chance que ir a la República Dominicana, único país que todavía admitía exiliados.

Nos dijeron que nos presentáramos como si fuéramos labradores que era lo que más interesaba a aquel país, pero como nunca nos han gustado los subterfugios, declaramos nuestra identidad de profesores y fuimos admitidos. (Después de todo nuestro oficio es labrar en cerebros). [...]

\section{(p. 60) SIGUIENDO LA RUTA DE CRISTÓBAL COLÓN, LLEGAMOS A LA «ESPAÑOLA»}

Embarcamos en Burdeos en enero 1940 y nos tuvieron en la desembocadura del Garonne lo menos quince días varados. Esperando la formación de un convoy mezclando barcos con pasajeros y otros cargados de material bélico. El barco "Cuba» ${ }^{14}$ había sido habilitado para carga humana convirtiendo las bodegas en dormitorios para los hombres, con literas de madera, desde luego más cómodas que el suelo de los campos de concentración.

Cuando por fin salimos, respiramos con gusto el olor a mar y aún con preocupación cantamos canciones folklóricas en las cuales todos encontrábamos igualdad. Todas las tardes a las cinco en punto sonaba una sirena de alarma que nos avisaba teníamos que hacer prácticas de salvamento. Estas consistían en que debíamos ponernos chalecos salvavidas y situarnos al lado de las lanchas preparadas para botarnos al agua, en caso de peligro. El primer día que lo hicimos resultó que a mi me habían asignado un puesto en una distante de la que le había tocado a Luis. Ante mis protestas un Sr. que iba solo se ofreció a cambiar con mi marido y así me quedé más tranquila. Mi circunferencia ecuatoriana aumentaba a medida que pasaban los días así que me costaba mucho

\footnotetext{
14 «En junio de 1940, durante los días de la ofensiva alemana sobre París, zarpó, con un cargamento de refugiados rumbo al exilio, el Cuba. ¿Destino? República Dominicana. A bordo iban seiscientos treinta refugiados cuyos pasajes habían sido costeados por el SERE en lo que constituía la duodécima expedición organizada desde Francia. El embarque se llevó a cabo en Burdeos. [...] La salida estaba prevista para el día 15, pero la situación de Francia y las negociaciones entre Hitler y Petain ralentizaron el proceso. Durante cuatro largos días los pasajeros esperaron a bordo del Cuba el final de las negociaciones. Mientras tanto, cada noche continuaban subiendo, de forma clandestina, nuevos refugiados judíos y algún que otro polizón» (Emilio Calle y Ada Simón, Los barcos del exilio (Madrid: Oberon, 2005), 177).
} 
ponerme el chaleco salvavidas. Además me había hecho «por si las moscas» una faltriquera de tela impermeable que amarrada a la cintura no me la quitaba ni para dormir. En ella llevaba documentos personales (títulos de estudios) algunos billetes y unas pocas joyas queridas, por si había que empeñarlas en un momento dado.

Decidimos alquilar sillas de extensión y dormir en la cubierta envueltos en mantas (era enero de 1940) ya que Luis no podía (p. 61) dormir en la bodega con aquellos olores (fedores, que decía él en bable) inclasificables.

Sobre mi litera puse el poco equipaje que teníamos en el suelo y la idea no pudo ser mejor ya que a la salida de Casablanca nos agarró una tempestad que inundó todos los pisos del barco con trombas de agua; al estar en alto, nuestra ropa se salvó de «ahogarse».

Supimos que habíamos sido rondados por submarinos alemanes pero, por lo visto, no nos consideraron presos que valiera la pena. Aunque y en otro viaje el "Cuba» fue hundido de todos modos. Tan solo por el nombre ya estábamos predestinados a ser víctimas de los enemigos de la libertad.

La tormenta nos afectó a todos (menos a mi marido) pues hasta los marinos y aviadores se marearon. No puedo decir que «cambiamos la peseta» porque no la teníamos, pero me acordé del viaje de mi papá a Filipinas pues también nosotros estuvimos inapetentes varios días, a pesar del hambre atrasada.

Cuando ya llegábamos a zona tropical cambió el aspecto de las personas. Con la tranquilidad de habernos alejado del peligro de la guerra, con el calorcito del sol en nuestros cuerpos, y la alegría de vivir, suprimimos la roba agobiante y se pudieron apreciar los cuerpos juveniles que salían de las crisálidas para convertir en mariposas.

Los peces voladores soltaban por encima de la cubierta, espectáculo nuevo para nosotros. Cuando vimos ramas flotando en el mar y oímos los chillidos de las gaviotas, nos dimos cuenta, como Colón, que la buena nueva tierra estaba cerca.

Durante la travesía leímos, prestado de la biblioteca el libro «Magallanes» escrito por nuestro compatriota Madariaga, y nos sirvió de 
mucho consuelo pues nuestro viaje era de naviero moderno griego comparándolo con el de nuestros ancestros.

(p. 62) Llegó el momento en que algún nuevo Rodrigo de Triana dijo o gritó «¡Tierra!». Contemplamos la capital de la República Dominicana, toda iluminada como una cintilla de brillantes, emocionados de ver por fin luces de noche, después de haber pasado varios años casi a oscuras por el temor de los bombardeos.

La euforia se apoderó de nosotros y bailábamos y nos abrazábamos fraternamente. Mientras se tramitaba el papeleo para desembarcar llegaban a cubierta cestos llenos de frutas tropicales como para curar el escorbuto sí hubiéramos tenido. Eran obsequios del público desconocido que nos esperaba y nos daba así la bienvenida. Por cierto, que lo que más me llamó la atención fueron unos frutos redondos y blancos que resultaron ser naranjas dulcísimas y ya peladas (la llaman chinas) con máquinas especiales que los vendedores tenían y utilizaban diestramente.

Ya en tierra una compatriota la preguntó a un guardia: «Y ahora ¿a donde nos llevan?», y al saber que podíamos hacer lo que nos viniera en gana, bien fuera ir a unos galpones mientras buscábamos algo mejor (ipero con toda LIBERTAD!) o, si teníamos dinero, acomodarnos en una fonda. Un grupo de nosotros nos fuimos a una fonda regentada por una Sra. italiana exuberantemente expresiva y gran cocinera la cual nos abrumó con comidas que nos resultaban pantagruélicas después de la dieta pasada. Y es que por un dólar diario no nos faltaban langostas, lomito, pollos, guineas, pasta con abundante salsa y sobre todo unas rodajas de piña tan dulce que parecían rociadas de azúcar.

Luis se presentó en el Ministerio de Educación y días después conseguía unas clases en la Normal de San Cristóbal, pueblo aspirante a ciudad capital por ser la tierra chica del Presidente Trujillo, situado a treinta kms. de la capital y que hubiera sido un paraíso para nosotros de no haber tenido serpientes. ¡El (p. 63) paludismo! Allí no había ningún doctor Gabaldón ya que el mosquito anopheles vivía y se reproducía feliz y en cantidad en los pastos húmedos y extensos de la dehesa del «Benefactor», como así era llamado el mandamás de la Isla, Trujillo. 
Durante dos meses vivimos en una habitación en la fonda de la «Filomena», una negra cincuentona con un corazón más blanco que la leche, suponiendo que ese color lo tienen los negros bondadosos, según la novela de Alberto Insúa «El negro que tenía el alma blanca».

Luego alquilamos una quintica (casita) y los primeros muebles los hizo Luís con cajones vacíos ya que nuestro "modus vivendi» era muy modesto. El pueblo dominicano es muy bondadoso y amable pero nunca tienen un "chele» (centavo) porque viven al día y gastan más de lo que ingresan. La mayoría de los empleados del gobierno (en aquellos tiempos) tenían adelantados por lo menos dos meses de su sueldo (el préstamo con interés era negocio del Jefazo) para tener ese dinero en mano si los botaban, cosa que no sorprendía a nadie. Hasta los Senadores y Diputados cuando iban a sus puestos miraban primero al portero para ver si con un movimiento de cabeza les indicaba que podían pasar. Si la movía negativamente se volvían para su casa pues era el modo de expresarles que estaban destituidos y regresaban al hogar a esperar los acontecimientos.

[...] Una mañana al ir Luis a clase le dijo el Director que le habían citado a la jefatura civil. Se presenta y después de hacerle esperar bastante tiempo el empleado le acusa de ingratitud, de haber hablado mal de las autoridades diciendo que la Isla estaba regentada por negros y otras muchas tonterías que nunca habían pasado por nuestra cabeza. (Luego supimos que todo provenía de una denuncia cursada por un alumno "pesado» a quien Luis había reprobado). En fin que de la noche a la mañana nos vemos destituidos de nuestros cargos de profesores (sin sueldo adelantado y sin prestaciones) y con la preocupación de males mayores. [...]

(p. 66) [...] Los funcionarios del gobierno con los que antes nos saludábamos volteaban la cabeza para no hacerlo al cruzarse con nosotros, por caer en desgracia ellos también. La única persona que, a voz en grito, salió en nuestra defensa fue la negra Filomena la cual despotricó contra Trujillo por la injusticia. (Ella podía permitirse esa libertad pues en tiempos lejanos hasta le había dado qué comer). La estancia en el pueblo se nos hacía insoportable, así que mal vendimos los muebles y nos trasladamos a la capital. Yo, sin saberlo Luis, escribí a la esposa de Trujillo (era española) contándole lo que había sucedido. 
Ya en Santo Domingo (entonces se llamaba Ciudad Trujillo) Luis comenzó a hacer gestiones para salir de la Isla. Hizo contactos con los cuáqueros, rama derivada del protestantismo que, siendo tan puritana, había sin embargo ayudado mucho a los republicanos, demostrando que el amor al prójimo no tiene política.

Había escrito a Loperena, entonces director del Colegio América en Caracas, Venezuela, y le había prometido a Luis una clase de Maestro (para empezar) con el sueldo, fabuloso entonces para nosotros, de Bs 450.00. Los cuáqueros prometieron a Luis pagarnos el pasaje del avión. Entre tanto habíamos recibido (caso inaudito) carta de la primera Dama comunicándonos que habíamos sido repuestos en nuestros cargos. Decidimos no aceptar, siendo así que los mismos compatriotas nos aconsejaban que nos fuéramos pues esa rectificación, casi única en los anales de la Isla, nos dejaba en una situación privilegiada.

La dueña de la casa de huéspedes donde vivíamos era republicana para baldón nuestro, pero lo que era resultó ser una alcahueta, ladrona, espía del régimen y vividora. Afortunadamente no recuerdo ni su nombre ni el de su marido el cual venía muchas veces del hospital donde trabajaba más gordo de lo natural por venir envuelto (p. 67) debajo de la camisa, en una sábana o toalla robada (nuevecita para poder venderla).

Ella era muy amable y me tenía embaucada con sus cariños a mis hijos. Sus piernas estaban llenas de pústulas, decía que por rascadas de picaduras de mosquito, pero después he pensado que algo más debía de tener pues solo del contacto con ella mis hijos tuvieron una infección que hubo que curarla con sulfa.

Lo de alcahueta lo digo porqué todas las mañanas esperaba la salida de un doctor español casado que venía a «dormir» con la querida, para cobrarle los dos pesos de su expansión.

No nos atrevimos a denunciar el robo al saber, por el mismo Dr., que ella era confidente de la policía y nuestra situación estaba de un equilibrio tan inestable que un empujoncito de ella nos podía hundir en el abismo.

No conseguíamos plaza en los aviones que venían de paso para Venezuela atestados con motivo de los juegos de Basevall del Caribe. Ante 
la esperanza de obtener aunque sea un puestecito, fuimos el 27 de Septiembre de 1944 (fecha de suerte para Luis) al Aeropuerto. Ya estaba dispuesta a salir yo sola con Nando, que tenía nueve meses y estaba con fiebre, cuando llamaron por el altavoz a Luis. Con temor de para que sería supimos la buena nueva de que había puesto para él también en el avión. Aún con la incertidumbre del futuro que nos esperaba... Qué felices hicimos el viaje, con solo cincuenta dólares prestados en el bolsillo! ${ }^{15}$

\section{(p. 68) ¡VENEZUELA!}

[...] Siguiendo a Colón salimos de «La Hispaniola» para llegar a la «Tierra de gracia». Ya la primera impresión nos resultó acogedora. Porque el aeropuerto estaba lleno de carteles que ostentaban el apellido de mi marido que parecían darnos la bienvenida. Eran de propaganda a favor de una candidata a Reina a presidir los Juegos del Caribe. Años después la conocimos personalmente conservando la belleza y simpatía que le habían hecho triunfar con el voto del proletariado, venciendo a la contraria, preferida por la clase bien.

Nuestro retraso en llegar dio como resultado que la vacante ofrecida a Luis ya había sido cubierta desde el 16 de septiembre, pero Loperena llevó a mi marido al Ministerio de Educación donde pronto le ofrecieron unas clases para un Liceo, en Valencia.

Recién llegados, nuestro buen amigo Gabriel nos trajo a la modesta fonda donde estábamos alojados, al doctor Gómez Malaret, para aten-

\footnotetext{
${ }^{15} \mathrm{El}$ caso del profesor Leal no fue único. Tal como afirma J. Ignacio Cruz «La contribución de los exiliados en el desarrollo de las instituciones educativas dominicanas fue amplia y fecunda, pero no fue duradera. Lamentablemente para la sociedad dominicana, las condiciones sociales y políticas del régimen trujillista impidieron que un significativo colectivo de republicanos se asentara definitivamente en la isla. A diferencia de lo que ocurrió en México, la República Dominicana debido a la miopía política de su dirigente, general Trujillo, no supo aprovechar el caudal humano que representaban los exiliados españoles para vivificar y desarrollar los sectores productivos y el sistema escolar. El exilio republicano en la República Dominicana no presenta, por tanto, un balance demasiado positivo. Pero tuvo un epílogo que le hizo adquirir un matiz amargo. La inquina del general Trujillo alcanzó con saña a algunos exiliados. Tres de ellos, Jesús de Galíndez, José Almoina y Alfredo Pereña fueron secuestrados y ejecutados por orden del dictador dominicano, en un atroz acto de venganza. Precisamente, los dos primeros habían sido profesores durante su estancia en la República Dominicana» (J. Ignacio Cruz, «Los profesores españoles exiliados en Santo Domingo», Cuadernos Republicanos 14 (1993): 116).
} 
der a nuestro hijo de la bronquitis que «importaba». Al nombrar a este doctor lo hago con la admiración, amor y respeto que se merece por lo bien que se portó siempre con los exiliados españoles. Él sabía lo que eso representaba pues también lo había sido en la época de Gómez ${ }^{16}$ viviendo en España donde se casó con una bella valenciana. ¡Quien iba a decirnos que pasados unos años morirían los dos en el mismo día! Supongo que si sus almas se han encontrado en alguna Galaxia podrán seguir intercambiando ideas afines.

Nos trasladamos a Valencia donde un español, Ramos, nos cedió para vivir la mitad de la quinta, donde él vivía solo.

Recién llegados a Caracas escribí al hogar vasco en mi condición de tal para ver si nos podían encontrar trabajo y cual sería nuestra sorpresa cuando recibimos una carta firmada por mi primo (p. 69) Ricardo Leizahola ${ }^{17}$ que deseaba verme. Vine a Caracas y me ofreció trabajo como administradora de un hotel que había tomado en traspaso y no podía atender debido a su ocupación profesional.

Luis y yo (siempre de acuerdo para todas las decisiones trascendentales) convinimos en aceptar el ofrecimiento por dos razones: Una el deseo de que mi hijo siguiera atendido por Gómez Malaret y la segunda el deseo de llegar a vivir en Caracas porqué el clima nos resultaba paradisíaco. Así que acepté ser patrona de Hotel yo que ni siquiera sabía manejar un hogar. Pero me adapté a las circunstancias y mi primo pudo cubrir los gastos, por lo menos. He sabido después que la época de mi administración fue cuando los huéspedes estuvieron mejor atendidos, ya que dado mi carácter los consideraba a todos como una gran familia y no economizaba en alimentos. Todos eran vascos, había jugadores de fútbol, ingenieros, constructores marinos, etc. y, para una vez que por variar acepté a una pareja de artistas colombianos, se fueron dejando dos meses de deuda y yo, agradecida a su marcha, no quise ni aceptar de ella una sortija que me quería dejar en prenda de sus buenas intenciones para pagar.

A este hotel iba con frecuencia el Dr. Aranguren, cirujano ya famoso donde hacía tertulia con otros vascos mientras esperaba la salida de sus hijos de un colegio cercano. Sin darle importancia y en la habitación

\footnotetext{
16 Juan Vicente Gómez, presidente del 1931 al 1936.

17 Hermano del Lehendakari. Fundador del Centro Vasco de Caracas. Editor.
} 
del hotel extirpó a Luis una fístula ciega que se le había formado antes de salir de la República Dominicana. Porqué a él también le atacó la fiebre palúdica y al ponerle una inyección un practicante desaliñado se le infectó por lo cual tuvo que soportar curas dolorosas aún sabiendo que con una penicilina se hubiera curado en 24 horas. Pero allá estos antibióticos estaban reservados, en aquellos tiempos, sólo para el ejército.

Recién llegado a Valencia le dio el paludismo otra vez y ese (p. 70) lo tuvo desesperado no tanto por la enfermedad sino porque ello le impedía ir a dar sus clases recién comenzadas. Le recomendaron como especialista en enfermedades tropicales al Dr. Félix Pifano el cual se interesó mucho en el caso de Luis ya que en Venezuela ese mal estaba erradicado. Dicho profesional resultó tan humano como el Dr. Gómez Malaret; fue más que doctor, un amigo y siempre recurrimos a ellos cuando nos fueron imprescindibles.

Instalada ya en Caracas con mis dos hijos todos los fines de semana venía Luis a vernos y hay que reconocer que el viaje en aquellos tiempos no era muy agradable. Seis horas para venir y otras seis para ir, bien fuera en tren o en autobús le suponían medio día de sacrificio.

Recuerdo que cuando fuimos a Valencia en tren nos resultó hasta divertido pues parecía de juguete al lado de los europeos. Pero la máquina tuvo fuerza suficiente para pasar sobre un pobre burro y los paisajes de Venezuela que contemplábamos por primera vez nos hicieron admirarla para siempre.

Al terminar el curso aprovechó Luis las vacaciones para gestionar en Caracas el conseguir clases que le permitieran radicar en la capital. Consiguió horas desperdigadas en distintos planteles privados y también en el Liceo Fermín Toro (oficial). [...]

(p. 73) Luis daba clase en el Colegio América (estaba de director el profesor Virgili) obtuvimos cupo para Marisa y Nando donde siguieron con su primaria y becados además. ${ }^{18}$ Luis siempre teniendo que despla-

\footnotetext{
${ }^{18}$ El Colegio América fue patrocinado el 1939 por un grupo de familias de la burguesía venezolana. Inicialmente la mayoría de profesores procedían del exilio republicano español, entre ellos: Josep Virgili, Maria Gili, Jesús Abadías, Alegría Campuzano, Harmonía Dalmau de Campuzano, José Pellisa, Miguel Renom, Tomàs Batrolí, Marc-Aureli Vila, Josep Vandelló, Ramon Torroja, Nuria Torroja, etc. El primer director fue Gabriel Loperena, amigo de Luís Leal.
} 
zarse de un Colegio a otro y además cursaba Filosofía en la Universidad Central para obtener un Título superior venezolano, trabajaba excesivamente. [...] (p. 74) Al crearse el Liceo Luis Ezpelezía y ser nombrado Director el competente Luis Echezuría, este solicitó del Ministerio que adscribieran a Luis con el nuevo personal ya que le había conocido en el Colegio América y le consideraba valioso para la enseñanza. Allí fue nombrado profesor de tiempo completo y eso le permitió renunciar a clases en el Instituto Escuela Florida ${ }^{19}$ donde, por no tener carro, se le hacía penoso ir.

[...] Después de dos años en San Bernardino ¡nueva mudanza! Esta vez a El Conde para estar cerca de un Colegio donde Luis acababa de aceptar el cargo de Director. Para consagrarse totalmente a él renunció a todos los demás planteles en los que daba clases y hasta a sus estudios universitarios, después de haber aprobado los dos primeros años de Filosofía con brillantes notas. [...] Cuando iba a finalizar el contrato de trabajo Luis quiso saber con alguna anticipación si le iba a ser renovado para, en caso contrario, buscar nuevo trabajo. Se lo dijeron tan a última hora, que no continuaría como Director, que ello dio lugar a corroborar mi otro slogan de que «cuando una puerta se cierra otra se abre».

Él se había acreditado como profesor y director habiendo aportado (p. 75) al colegio buenos profesores y aumentado la matrícula en un $25 \%$ en número de alumnos. Pero la hija del dueño del Colegio regresó de España, a última hora, y quiso hacerse cargo de la dirección del Colegio.

Ello motivó que iniciáramos un nuevo rumbo a nuestras vidas. Porque Luis, que tenía carisma para dirigir más que para obedecer, se dio el gusto a su vocación plenamente. Decidió poner un Colegio donde aplicar sus teorías pedagógicas, sin más trabas que las impuestas por el medio y el Ministro de Educación. Gracias a Esperanza supimos de una quinta desalquilada bastante grande y la alquilamos, jugándonos el todo por el todo. Nueva mudanza para economizar gastos

\footnotetext{
${ }^{19}$ Creado el 1940 por Bartomeu Oliver, estaba guiado por las ideas pedagógicas de la Institución Libre de Enseñanza y los principios de la Escuela Activa. Igual que otros colegios dirigidos por maestros republicanos exiliados en La Florida trabajaron Dolors Jordana, esposa de Bartomeu Oliver, Domingo Casanovas, August Pi Sunyer, Pere Grases, Marçal Pascuchi, Joan Campà, Clotilde Chacón, etc.
} 
apañándonos como pudimos en un rincón después de hacer obras de adaptación. ${ }^{20}$

\section{¡COLEGIO LEAL! (p. 76)}

La ilusión, el entusiasmo, la celebración de todos al iniciar esta nueva etapa de nuestra vida es inenarrable. La fidelidad y el afecto demostrado por los alumnos de Luis le hace pensar solamente en no defraudarles en su deseo de cambiar los cánones pedagógicos estrictos por otros que imponen los tiempos modernos.

Y las frases «echarle pichón» $\mathrm{y}$ «manos a la obra», tan de moda posteriormente en boca de dos Presidentes de la República, las llevamos a la práctica todos en aquellos años, a partir del 1953.

Para demostrar la verdad de lo que afirmo, nada mejor que copiar al pie de la letra un trabajo hecho por una alumna explicando a los compañeros el origen de la fundación del Colegio. (Hoy ésta que fue alumna tiene un cargo relevante en la Universidad y su nombre, por qué no decirlo, es Amaya Llebot Casalis).

«Estoy segura de que los nuevos alumnos del colegio, al ver a los más antiguos tan orgullosos del mismo se han preguntado más de una vez: ¿Cómo, cuándo y por qué se fundó el colegio? ¿Cual es su historia, que intención tuvo su fundador al crearlo? ¿Por qué estos muchachos que están en él desde el primer día lo aman tanto? Puesto que formo parte de este grupo inicial y quiero a mi colegio como si fuera un poquitín mío, voy a intentar explicar la historia del Colegio y la de nuestra compenetración con su Director.

Muchos de nosotros venimos estudiando bajo la dirección del profesor Leal desde quinto grado; algunos desde antes ya que fueron sus alumnos en el Colegio América. Yo puedo recordar ahora -y eso que a

\footnotetext{
${ }^{20}$ Sobre la actuación de los profesores republicanos exiliados en Venezuela, escribimos: «Algunos de ellos y ellas procurarán mantener la fidelidad pedagógica esforzándose en inculcar sus ideales educativos, fruto de las opciones políticas concretas. Se esforzarán para que los ideales de educación en libertad y la tolerancia se practiquen a lo largo de los diversos signos ideológicos y políticos de los gobiernos de Venezuela que oscilaron entre la democracia y la dictadura, con dos golpes de estado de por medio, trabajarán para que los aprendizajes sean activos y respondan a las propuestas del movimiento de la Escuela Nueva, etc.». Cf. Marquès Sureda-Martín Frechilla, La labor educativa, 216.
} 
veces me parece que todo está muy lejos- el primer curso que en el colegio Caobos tuvimos al Profesor en la dirección. Y puedo recordar también con cuanto asombro y disgusto supimos muchos, dos cursos después, que nuestro Director se separaba del plantel. Fue más o menos el día 27 de julio de 1953. Me parece que esa fecha es la (p. 77) que sirve para decir: en ese día se fundó el colegio «LEAL». ¿Que todavía no existía materialmente hablando? Claro está. Pero ¿verdad, Profesor, que en ese momento pensó $\mathrm{Vd}$. ya en que iba a realizarse su sueño de tener un colegio propio, organizado y dirigido por Ud., algo así como un hijo, parte de usted mismo?

Sigo recordando. Ya está la idea del Colegio en marcha, ya muchos de sus antiguos alumnos se le acercan —al Profesor- rogándole que se decida. Ahí empiezan las dificultades y los trabajos. Surge el primer gran problema: ¿Donde instalarse? El tiempo apremia. Calle arriba, calle abajo; al Este, al Centro, El Rosal, Las Mercedes, San Bernardino. Hasta que un día su hermana Esperanza encuentra algo: una casa al Sur 21, una de las que hoy ocupamos. Dos semanas después se obtiene la otra. ¡Vaya, las cosas no están saliendo tan mal! No, por favor, no se ilusionen; ahora es que falta ¿Y los Profesores? ¿Y el material escolar? $¿ \mathrm{Y}$ - no se ofenda Profesor- el dinero?

Ya estamos lanzados. Digo estamos, porque muchos de sus antiguos alumnos, estábamos también en plan de combate: «Mami que a mi no me inscriban en otro lugar; mira que el Profesor va abrir un nuevo Colegio...». Repito: nos lanzamos a buscar Profesores; ya los tenemos, dispuestos a hacer sacrificios para que el sueño de un pedagogo se haga realidad. Todos hallan tiempo, todos ponen su parte de entusiasmo. Pero comienza el material a faltar y estamos a principios de septiembre. Todo ha de estar listo para el 15 de este mes. ¿Qué hacer? En carro, en autobús, caminando, a recorrer Caracas otra vez, como antes en busca de casa, ahora en busca de muebles, de materiales, de créditos. El 5 de agosto se había abierto las inscripciones. Para sorpresa del Profesor y de su Sra. la inmensa mayoría de sus alumnos seguían siendo "fieles" a su Director y venían a inscribirse. Todas se conocen, todos se saludan con un «Tú también» que expresa entusiasmo y alegría.

(p. 78) Ha llegado el 15 de septiembre de 1953. Se han superado los obstáculos. Las dos casitas están llenas de una muchachada alborota- 
dora que se saluda con emoción. ¡Si casi todos se conocen, si son viejos compañeros, si las casas han quedado bellísimas, los Profesores rebosan de amabilidad (es el primer día, no lo olvidemos) y todo está (¿lo digo?)... la CÁTEDRA!.

Ha llegado el día 15 y el colegio comienza sus clases. Primaria ocupa una de las casas, junto con la Dirección y la secretaría que corre a cargo de la Sra. Leal «Fiel». Bachillerato ocupa la otra casa. Allí, los profesores: Echezuría, Totesaut, Silvia Jaimes, Fernández, Bruzual, Arias, Ventura Gómez y un etc. que incluye a los varios y tan queridos y competentes como los primeros, se hicieron cargo de nosotros y ayudaron al profesor con todo entusiasmo.

Y no es extraño que no cite al grupo de Profesores de Primaria: yo llegué al Colegio a empezar mi primer año de bachillerato y, naturalmente, poco recuerdo de la organización de Primaria ni de sus Profesores y alumnos. ${ }^{21}$

En este primer año de actividades fueron elegidas las primeras Reinas del colegio: Martha Elena Montsant por Bachillerato y Celina García por Primaria. Estudiamos bastante, tuvimos algunas fiestas además de la Coronación de las Reinas, y al terminar el curso nos sentimos un poco colaboradores del Profesor. Tal vez era vanidad, y en lo único que colaboramos fue en crearle problemas. Como sea, aquel primer curso es uno de los más gratos en nuestro recuerdo.

Tras las vacaciones de 1954 - que, como todas, fueron cortas y pasaron rápidamente- nos hallamos en el 2. ${ }^{\circ}$ año del Colegio. Muchas imperfecciones se corrigieron en él, muchas nuevas actividades se crearon: un Cuarto Año de bachillerato, que no existía anteriormente, inició y terminó su curso, pasando a ser la primera promoción del Colegio. Se fueron en 1955, pero ligados siempre al colegio por recuerdos y cariño (p. 79) no pasa día sin que varios de ellos nos acompañen en los patios y salones. También tuvimos un equipo de Volley-Ball ¡Y qué equipo! Arrasó con los premios de competencias con otros colegios y adornó la Dirección con Copas y medallas.

\footnotetext{
${ }^{21}$ En el Colegio Leal inicialmente ejercieron profesores republicanos exiliados, entre ellos, además de Pilar Munárriz, su esposa, Esperanza Leal, su hermana, Adolfo Fernández, Visitación Jiménez, Paula Mateo, Begoña Larrañaga, etc.
} 
Sus triunfos se comentaron en la Prensa y en otros Planteles y seguro que hasta se envidiaron un poquito. Y nos dieron motivos para fiestas, presididas por las Reinas de este año. Mireya Seijo de bachillerato y Mónica Arroyo de primaria. Fue, además, Mireya, la capitana del equipo de Volley-Ball juvenil. Aun gozamos de otra satisfacción más: nuestra compañera Garbiñe Echevarria, fue electa Reina de un torneo con otros colegios.

Esta es la historia de nuestro Colegio, que inicia su tercer año de labores. Tenemos buenos maestros que nos guían, un grupo de ex-alumnos que nos apoyan y estiman, reina entre nosotros el compañerismo y nuestro Director parece satisfecho de la obra que en nosotros y por nosotros está realizando. Nos queda entonces ser "fieles" hasta el fin y hacer honor a nuestro querido, inolvidable Colegio».

[...] Luis dio clases de Geografía, Historia, Francés, y de todo un poco cuando tenía que suplir la falta de algún profesor. Yo, a su vera, le ayudé en todo lo que mis facultades me lo permitieron teniendo que hacer el primer año hasta la comida para unos doce niños seminternos ya que el servicio aún en aquellos tiempos era escaso. Vivíamos en el propio Colegio para economizar gastos.

(p. 80) Luis se decidió a aprender a manejar con el fin de poder hacer excursiones al Litoral, los fines de semana, para reparar fuerzas y almacenar salud. Luego nos mudamos a un apartamento en un edificio contiguo al Colegio, y así seguimos con nuestra más o menos rutina hasta diciembre del 57 en que acometimos la aventura de ir a conocer Canaima en vísperas del GRAN GOLPE del 23 de enero de $1958 .^{22}[\ldots]$

\section{(p. 84) ¡EL VEINTITRÉS DE ENERO! SEGUIMOS INFORMANDO}

[..... El Colegio estaba a una cuadra de la sede de la temida Seguridad Nacional por delante de la cual pocos se atrevían a pasar. El 23 de enero de 1958, después de ver por el aire «La vaca sagrada» o sea el avión que se llevaba a Pérez Jiménez, el pueblo jubiloso se echó a la calle y toda la mañana desfilaron por delante de nosotros todas las cla-

\footnotetext{
${ }^{22}$ Se refiere al golpe de estado que puso fin a la dictadura del general Marcos Pérez Jiménez.
} 
ses sociales para festejar el acontecimiento, abrazándose unos a otros y queriendo presenciar la caída de la «Bastilla» y la salida de los presos políticos que en ella se encontraban.

Tuvimos nuestra parte de emoción y susto. Porque una de las veces se refugió en la quinta un joven haciéndonos ver que era preso político y lo recibimos con todos los honores. Pero luego sospechamos que no debía ser un preso, sino un empleado de oficina que había podido escabullirse y respiramos cuando en un momento de tranquilidad en la calle pudimos verlo abandonar la casa.

Cuando el ejército decidió asaltar el edificio nos recomendaron (p. 85) (Luis estaba todo el rato en la puerta vigilante) que nos retiráramos al fondo de la casa pues habría tiroteos. En efecto, oímos algunos disparos y sentimos que estaban trepando por la fachada de la quinta unos asaltantes. Luis les abrió la puerta ya que decían que en la terraza estaban disparando Pérez Jimenistas. Resultó que era el eco lo que lo hacía parecer. En el grupo venía un estudiante que reconoció a mi marido y respondió por él. Menos mal porque uno de ellos al abrir yo el escaparate agarró con disimulo mi cartera y Luis le reprobó el acto preguntándole que si era revolucionario o ladrón. Al marcharse (con una botella de wisky que les regalé después de echarse unos tragos directos del envase) empezaban a entrar otros en avalancha, creyendo podían saquear como ya lo habían hecho en la Avenida México. Les impresionó la presencia de "Trueno» ladrando y enseñando sus agudos colmillos que Nando a duras penas podía contener sujetándolo del collar. También tengo la estampa grabada de Marisa agarrando a uno de ellos, que se iba a meter en su cuarto, y que tenía manchas de sangre en la camisa y diciéndole furiosa que allí no tenía nada que hacer. Y él mansito la obedeció mientras que a mi me había dicho momentos antes «ivieja cállate!». (¡Oh poder de la juventud y de la belleza!).

Así como en la mañana ese 23 de enero había sido eufórico, lleno de alegría, con aquel desfile de entusiastas y curiosos que daban colorido a la calle, por la tarde cambió el aspecto viéndose el lumpen que con cabillas y cuchillos rompían carros y quemaban muebles y colchones, sacados de casas de huéspedes que se sospechaba habían albergado a gente de la Seguridad Nacional. Algunas personas que habían estacionado sus carros en calles adyacentes los encontraron quemados, a 
causa del desahogo de las masas, ya incontenibles a última hora. En la noche todo quedó tranquilo y al cabo de unos días reanudamos clases, al principio un poco alborotadas a causa de que todos querían, (p. 86) como es lógico, comentar los acontecimientos vividos por cada uno. Los profesores se abrazaban emocionados y contentos ya que la mayoría eran demócratas que por sus ideas habían sido relegados de sus puestos oficiales y habían encontrado en nuestro colegio la acogida que, dados sus méritos pedagógicos, se merecían. [...]

Terminamos el curso con la satisfacción de graduar de bachilleres en Ciencias y Humanidades a los alumnos que habían comenzado el primer año con nosotros. [...] (p. 87) Cuando se iban a reanudar las clases en septiembre comenzaron nuestros problemas. La mayoría de los profesores tuvieron que dejarnos para colaborar con el nuevo gobierno en puestos claves y de confianza. Muchos alumnos se inscribieron en Liceos oficiales, que se abrieron aquel año, y el carácter gratuito ahorraba a los padres el dispendio de un Colegio de pago. En fin que tuvimos que reducirnos y nos quedamos con primaria y tres años de bachillerato (Ciclo básico).

Los años posteriores fueron de cuesta abajo para el Colegio porqué teníamos un contingente de alumnos que vivían en la urbanización El Conde, la cual se mandó demoler con el fin de construir luego el Parque Central. Muchas familias se trasladaron al Este de Caracas y allí encontraron Colegios más cercanos al nuevo hogar. Así que nos quedaron solo los alumnos suficientes, justo para cubrir los gastos del Colegio y para cubrir los nuestros. Luis daba clases en el Andrés Bello y en el Instituto Pedagógico, en horas que podía ausentarse. [...]

(p. 89) Nuestros tres hijos tuvieron oportunidades de ayudarnos en el Colegio y demostraron aptitudes pedagógicas, pero ninguno estuvo dispuesto a seguir nuestros pasos en la enseñanza. Decían que nos habían visto a los dos muy sacrificados, trabajando hasta los domingos, mientras los demás tenían sus días de vacación y descanso y ellos deseaban gozar un poco de la vida. Lo que no se daban cuenta es que Luis y yo éramos felices con nuestro trabajo para el que teníamos verdadera vocación. [...] 


\section{(p. 92) Y AQUÍ DOY FIN A MIS MEMORIAS, CON LA MUERTE} DE MI OTRO «YO»

Año 1973 comienza nuestra cuesta abajo con el Colegio y en nuestra vida. El Presidente de la república ${ }^{23}$ emite para el 1 de mayo un decreto de avances sociales muy importantes pero que a nosotros nos llevan a la debacle. Se ordena aumentar los sueldos en una escala proporcionada que a nosotros nos representa el $25 \%$ más en los gastos del colegio. Al mismo tiempo nos prohíben aumentar las pensiones que pagan los alumnos. Estas eran tan modestas que los gastos igualaban a los ingresos desde hacía mucho tiempo. Habíamos tenido años de déficit, pero el éxito alcanzado por los alumnos en el concurso de Televisión «Aquí Oscar, competencia de Juventud» donde tanto los de primaria como los de secundaria habían salido campeones, sirvió para que nos aumentara la matrícula, lo cual demuestra que la juventud sí quiere estudiar. Gracias a esto y a que Luis y yo percibíamos una cantidad mínima de sueldo (menor de la de algunos de los Profesores y nosotros nos defendíamos, pero... ¿qué íbamos a hacer ahora?).

Luis tan cumplidor de la ley, se llena de preocupaciones. Si bien los mismos profesores, capitaneados por Oche le dicen que ellos no exigen nada por el momento, en espera de que el Ministerio de Educación pensione a los Colegios, la preocupación de mi marido no le deja dormir. Le sube la tensión de modo que le afecta el glaucoma de sus ojos y de repente se encuentra ciego.

De acuerdo nuestros hijos con el abogado del Colegio se hace una reunión con el personal y se aprueba la propuesta de hacerse cargo del Colegio y administrarse ellos mismos en espera de la prometida subvención, y Luis queda libre para atender a su precaria salud, conmigo de enfermera, naturalmente. Luis tenía 71 años. Luis tenía una modesta jubilación por sus clases en Liceos oficiales y con ella nos defendíamos.

(p. 93) Al año de esta situación y dándonos cuenta que la ociosidad le perjudica en su ánimo aceptamos la solicitud de ir de vez en cuando por el Colegio, ya que Luis aunque sea de palabra puede asesorar al personal que se lo solicite, y yo me hago cargo de la biblioteca, que está sin ordenar ni clasificar, y así percibo un modesto sueldo que ayuda

\footnotetext{
${ }^{23}$ Rafael Caldera (1969-1974)
} 
para la compra de las medicinas bastante costosas. Porque por culpa de la falta de vista Luis un día cae por una escalera y se aplasta dos vértebras de la columna que le obligan a usar un corsé molesto unos cuantos meses.

Y así se desliza nuestra vida hasta que en diciembre del 75 con motivo de un, al parecer, simple catarro mal curado le hacen una radiografía y aparece algo en el pulmón. El doctor, con la esperanza de que el tumor descubierto pueda extirparse, decide operarlo. ¡Nada puede ya hacerse! Cáncer invasivo del pulmón ¿A que seguir contando más calamidades que renuevan mi tristeza con estos amargos recuerdos?

El 14 de abril, fecha que como buen republicano le había gustado siempre celebrar y coincidiendo ese año con el miércoles de Semana Santa, su corazón dejó de latir. Como todo el mundo estaba de vacaciones fueron pocas las personas que se enteraron de su deceso, así que lo enterramos discretamente, como, de todos modos, a él le hubiera gustado. $[\ldots]$

(p. 100) [...] Y para terminar con un broche de oro sobre vuestro querido padre y abuelo en cuyo honor y homenaje he mal escrito estas memorias voy a copiar lo que, al año de su muerte, publicó en el Nacional un profesor, abogado y periodista muy destacado en Venezuela y que, como había dado clases en nuestro Colegio, podía escribir sobre él con conocimiento de causa.

\section{EL PROFESOR LEAL}

«Ahora se cumple un año de la muerte de este hombre ocurrida con el mismo silencio y la austeridad con que vivió. Silencio creador, el suyo. Como que dedicó su vida, bastante prolongada, a la educación de los jóvenes. Llegó a Venezuela, con doña Pilar, su inseparable compañera, hace muchos años, aventado por la tragedia de España, que siempre llevó en lo más hondo de su entraña, y de la que nunca se repuso. Aquí pudo hacer fortuna, en una época en la que la enseñanza se hizo negocio lucrativo. El prefirió cumplir su labor, en su Colegio LEAL, sin ir más allá de lo que él mismo personalmente podía atender, vigilar, supervisar... Aunque le produjese menos dinero. En compensación, mejores frutos en el logro de una educación esmerada, de una enseñanza 
más exigente, de una formación más sólida... Y de paso, inevitablemente, la inestimable dicha de saberse vivo en el recuerdo de muchos jóvenes, de muchos profesionales que alguna vez pasaron por sus manos, en las aulas de su pequeño colegio.

Venezuela está en deuda con este hombre.

Alexis Márquez Rodríguez».

Solo me queda decir por mi parte: la deuda está saldada con este bello panegírico.

\section{(p. 101) COLOFÓN}

Entre sus escritos encuentro, de 1971, la siguiente alocución, que transcribo, dirigida a los alumnos del Liceo Andrés Bello y que lo considero como un TESTAMENTO A LA JUVENTUD VENEZOLANA, en la que están incluidos hijos y nietos:

«Queridos bachilleres.

He sido designado para dirigiros la palabra en este acto de graduación. Y en verdad que "en mi vida me he visto en tal aprieto" como dijera el poeta.

Que ¿por qué?

Fácil es de comprender que a mis años dirigirme a vosotros en este solemne acto, jóvenes bachilleres, no es empresa sencilla.

Vosotros sois la juventud, el optimismo, la esperanza de un mundo mejor, el porvenir, el mañana...

Yo, por el contrario, salta a la vista, soy el presente cargado del ayer, del pasado, del recuerdo y del olvido.

Entre vosotros y yo está todo este violento y tenebroso siglo veinte que ya marcha velozmente a su fin.

Cada uno de vosotros va a emprender una nueva etapa, un nuevo camino en el hacer de vuestras vidas. 
Dejadme que os recuerde aquellos versos del gran poeta Antonio Machado:

\author{
Caminante, no hay camino, \\ se hace camino al andar. \\ $\mathrm{Al}$ andar se hace camino, \\ y al volver la vista atrás \\ se ve la senda que nunca \\ se ha de volver a pisar...
}

Y eso es lo que os pido: Abrid con firmeza, con tesón, con entusiasmo vuestro camino al andar y pensad que esos caminos vuestros son los caminos de la Patria, de Venezuela, de esta tierra de Gracia, en la que yo encontré el calor que buscaba y la Libertad por la que en mi juventud luché al otro lado del Atlántico.

Sed fieles, leales a vuestros ideales, pero sed tolerantes.

No olvidéis que Moral y Luces siguen siendo nuestras primeras necesidades... Luchad por la fraternidad y la libertad de los hombres en la dignidad de una Venezuela mejor y de un mundo de todos.

\title{
QUE DIOS OS BENDIGA.
}

Gracias».

\section{Nota sobre el autor}

Salomó Marqués Sureda es actualmente profesor jubilado de Historia de la Educación en el Departamento de Pedagogía de la Universitat de Girona. Fue presidente de la Societat d'història de la Educació dels Països de Llengua Catalana desde el 2002 al 2015 ,y es miembro del Consell Científic del Museu Memorial de l'Exili (MUME) de La Jonquera. Su principal campo de investigación en las últimas décadas se ha centrado en la escuela republicana i franquista en Cataluña. De manera especial en el estudio de la depuración y exilio del magisterio primario.

Es autor de artículos publicados en revistas especializadas nacionales y extranjeras, así como de libros científicos y de divulgación. También ha colaborado en programas de radio, televisión y actividades de asesora- 
miento sobre temas relacionados con el exilio del magisterio, la Segunda República y la dictadura franquista. De entre sus publicaciones destacan: L'exili dels mestres (1939-1975), Girona, Universitat de Girona, 1995; L'escola pública durant el franquisme. La província de Girona (1939-1955), Barcelona, PPU, Barcelona, 1992; Martí Rouret, mestre, republicà i català, Ajuntament de l'Escala, 2001, existe una edición por El Colegio de Jalisco, en Guadalajara (Jalisco, México); Los hermanos Bargés Barba maestros renovadores en Cataluña y México, El Colegio de Jalisco-Generalitat de Catalunya, Zapopan, Jalisco, 2004; Els mestres de la República, Ara Llibres, Barcelona, 2006, en colaboración con Raimon Portell; El magisteri gironí d'Esquerra a l'exili del 1939, Fundació Josep Irla, Barcelona, 2009; Educación republicana en Cataluña y Torreón, Instituto Nacional de Antropología e Historia, Jalisco (México), 2011; y Miquel Santaló i Parvorell, professor i polític republicà, Pagès Editors, 2015.

\section{REFERENCIAS}

Calle, Emilio y Ada Simón. Los barcos del exilio. Madrid: Oberon, 2005.

Cruz, Ignacio. «Los profesores españoles exiliados en Santo Domingo», Cuadernos Republicanos 14 (1993): 107-116.

Juhera i Cals, Miquel, La Inspecció d'Ensenyament des dels seus origens a la Segona República. Edición privada ciclostilada.

Marquès Sureda, Salomó-Juan José Martín Frechilla. La labor educativa de los exiliados españoles en Venezuela. Caracas: Fondo Editorial de Humanidades y Educación, Universidad Central de Venezuela, 2002.

Puigbert, Joan. La Normal de Girona i el magisteri públic (1914-1936). Girona: Universitat de Girona, 1994. 